\title{
National Preclinical Sepsis Platform: developing a framework for accelerating innovation in Canadian sepsis research
}

\author{
Asher A. Mendelson 1,2, Casey Lansdell ${ }^{3}$, Alison E. Fox-Robichaud ${ }^{4,5}$, Patricia Liaw ${ }^{4,5}$, Jaskirat Arora ${ }^{5,6}$,

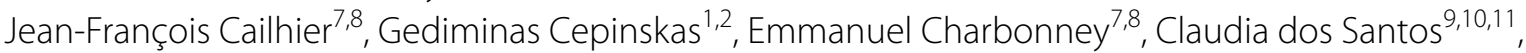 \\ Dhruva Dwivedi ${ }^{4,5}$, Christopher G. Ellis ${ }^{1,12}$, Dean Fergusson ${ }^{13}$, Kirsten Fiest ${ }^{14}$, Sean E. Gill ${ }^{2,15,30}$, \\ Kathryn Hendrick ${ }^{16}$, Victoria T. Hunniford ${ }^{13}$, Paulina M. Kowalewska ${ }^{12}$, Karla Krewulak ${ }^{14}$, Christian Lehmann ${ }^{17}$, \\ Kimberly Macala ${ }^{18}$, John C. Marshall 9,10,19,31 , Laura Mawdsley ${ }^{1}$, Braedon McDonald ${ }^{14,20}$, Ellen McDonald ${ }^{4,5}$, \\ Sarah K. Medeiros ${ }^{5,6}$, Valdirene S. Muniz ${ }^{4,5}$, Marcin Osuchowski ${ }^{21}$, Justin Presseau ${ }^{13,22}$, Neha Sharma ${ }^{5,6}$, \\ Sahar Sohrabipour ${ }^{5,6}$, Janet Sunohara-Neilson ${ }^{23}$, Gloria Vázquez-Grande ${ }^{24,25}$, Ruud A. W. Veldhuizen 2,15,30, \\ Donald Welsh ${ }^{12,15,30}$, Brent W. Winston 20,26,32, Ryan Zarychanski ${ }^{24,27}$, Haibo Zhang 9,28,33, Juan Zhou ${ }^{17}$ and \\ Manoj M. Lalu ${ }^{13,29^{*}}$ (D) on behalf of Sepsis Canada's National Preclinical Sepsis Platform
}

*Correspondence:

mlalu@toh.ca

${ }^{29}$ Department

of Anesthesiology and Pain Medicine, The Ottawa

Hospital, 501 Smyth Road, PO Box 201B, Ottawa, ON K1H

8L6, Canada

Full list of author information

is available at the end of the article

\begin{abstract}
Despite decades of preclinical research, no experimentally derived therapies for sepsis have been successfully adopted into routine clinical practice. Factors that contribute to this crisis of translation include poor representation by preclinical models of the complex human condition of sepsis, bias in preclinical studies, as well as limitations of single-laboratory methodology. To overcome some of these shortcomings, multicentre preclinical studies - defined as a research experiment conducted in two or more research laboratories with a common protocol and analysis - are expected to maximize transparency, improve reproducibility, and enhance generalizability. The ultimate objective is to increase the efficiency and efficacy of bench-to-bedside translation for preclinical sepsis research and improve outcomes for patients with life-threatening infection. To this end, we organized the first meeting of the National Preclinical Sepsis Platform (NPSP). This multicentre preclinical research collaboration of Canadian sepsis researchers and stakeholders was established to study the pathophysiology of sepsis and accelerate movement of promising therapeutics into early phase clinical trials. Integrated knowledge translation and shared decision-making were emphasized to ensure the goals of the platform align with clinical researchers and patient partners. 29 participants from 10 independent labs attended and discussed four main topics: (1) objectives of the platform; (2) animal models of sepsis; (3) multicentre methodology and (4) outcomes for evaluation. A PIRO model (predisposition, insult, response, organ dysfunction) for experimental design was proposed to strengthen linkages with interdisciplinary researchers and key stakeholders. This platform represents an important resource for maximizing translational impact of preclinical sepsis research.
\end{abstract} party material in this article are included in the article's Creative Commons licence, unless indicated otherwise in a credit line to the material. If material is not included in the article's Creative Commons licence and your intended use is not permitted by statutory regulation or exceeds the permitted use, you will need to obtain permission directly from the copyright holder. To view a copy of this licence, visit http:// creativecommons.org/licenses/by/4.0/. 
Keywords: Sepsis, Experimental models of sepsis, Multicentre preclinical, Translation, Reproducibility, Multi-stakeholder, Integrated knowledge translation, PIRO

\section{Background and rationale}

Sepsis is the life-threatening organ dysfunction caused by a dysregulated host response to infection [1] and accounts for one-fifth of all deaths worldwide [2]. In 2017, the World Health Organization adopted a resolution to improve the prevention, diagnosis and clinical management of sepsis [3]. Preclinical sepsis research-defined here as laboratorybased animal and basic science research-plays an essential role in this overall strategy, and has contributed substantially to our understanding of sepsis pathobiology and organ dysfunction [4, 5]. However, despite decades of preclinical research findings, there remains no experimentally derived therapies for sepsis successfully adopted into routine clinical practice [6].

Several factors contribute to impediments in translation to the bedside as described in Table 1. Clinical sepsis is highly heterogenous, and imperfectly reflected in a single animal model. These animal models are frequently criticized for inadequately representing and over-simplifying the sepsis syndrome. For example, research animals are often genetically identical, and almost exclusively healthy (no pre-morbid conditions, co-interventions, medications and/or environmental stressors). Moreover, historically, significant sex bias has led to under-representation of female animals in sepsis experiments, and although recent efforts have been made to address these disparities, sexbased analysis continues to be underreported [7]. In addition, sepsis is often mimicked with non-bacterial surrogates (e.g. endotoxin) that may reduce validity of findings. Conversely, when true models of infection are used polymicrobial abdominal sepsis is the prevailing locus of infection, which may reduce generalizability to other forms of sepsis. There is also a disconnect from clinical management as standard therapies for sepsis (e.g. antibiotics, intravenous fluids, mechanical ventilation) are often omitted in experimental models. Similarly, novel therapeutics are often tested in these animal models as a pre- or co-treatment with septic inoculation, a timing of intervention that has little clinical correlation. Practically, it is often difficult to maintain septic animals for prolonged periods of time, to successfully institute life support over days, and to follow the natural history of sepsis survival and recovery (weeks to months). Ethical considerations for humane animal care limit direct observations of organ failure and mortality, and preclinical endpoints do not always function as appropriate surrogates for clinical outcomes. Finally, consideration for variability in host response and outcome (even in genetically identical animals) is rarely accounted for, leading to inadequately powered studies using small groups of animals.

Another factor affecting the translational potential of preclinical sepsis research is that findings are mostly derived from single investigator/laboratory studies with a bias towards publishing positive results, and concerns with reproducibility and methodological rigour are frequently noted (i.e. lack of sample size calculation, randomization, blinding) $[8,9]$. Although the ARRIVE guidelines were introduced as an effort to improve transparency and consistency in preclinical research [10], they have not been consistently adopted. In preclinical sepsis research, significant variations in experimental practice and animal housing/husbandry exist [11], and reporting of experimental methods 
Table 1 Potential factors contributing to the lack of "bench-to-bedside" translational success of preclinical sepsis research

\begin{tabular}{|c|c|c|}
\hline Domain & Preclinical model & Human condition \\
\hline \multicolumn{3}{|l|}{ Construct validity } \\
\hline Patient population & $\begin{array}{l}\text { Historically male, however more female } \\
\text { animals in recent years } \\
\text { Healthy } \\
\text { Young/juvenile } \\
\text { Limited environmental exposure } \\
\text { Genetically homogeneous }\end{array}$ & $\begin{array}{l}\text { Female and male } \\
\text { Medical comorbidities } \\
\text { Old and young } \\
\text { Environmental stressors } \\
\text { Genetically diverse }\end{array}$ \\
\hline Site of infection & $\begin{array}{l}\text { Non-bacterial surrogates (e.g. endotoxin) } \\
\text { Polymicrobial abdominal/enteric Gram- } \\
\text { negative } \\
\text { Pneumonia (rare) } \\
\text { Fungi/protozoa (rare) } \\
\text { Virus (very rare) }\end{array}$ & $\begin{array}{l}\text { Soft tissue Gram-positive } \\
\text { Abdominal Gram-negative, including biliary } \\
\text { Pneumonia (common) } \\
\text { Virus (common) } \\
\text { Fungi/protozoa }\end{array}$ \\
\hline Intercurrent therapy & $\begin{array}{l}\text { None } \\
\text { Antibiotics (monotherapy) } \\
\text { Fluids } \\
\text { Anesthesia/analgesia } \\
\text { Experimental therapy }\end{array}$ & $\begin{array}{l}\text { Antibiotics (poly-therapy) } \\
\text { Fluids } \\
\text { Blood products } \\
\text { Vasopressors/Inotropes } \\
\text { Sedation/analgesia } \\
\text { Baseline medication regimen } \\
\text { Adjunct therapies (e.g. steroids, heparin) }\end{array}$ \\
\hline Outcomes & $\begin{array}{l}\text { Non-mortality surrogate } \\
\text { Short term } \\
\text { Organ failure (often single) } \\
\text { Molecular biomarkers (common) } \\
\text { Organ histology }\end{array}$ & $\begin{array}{l}\text { Mortality } \\
\text { Short and long term } \\
\text { ICU/hospital length of stay } \\
\text { Validated multi-organ failure score } \\
\text { Molecular biomarkers (rare) } \\
\text { Organ histology (very rare) }\end{array}$ \\
\hline \multicolumn{3}{|l|}{ Research methodology } \\
\hline Biostatistics & Lack of sample size calculation & $\begin{array}{l}\text { Study powered to detect difference in pre- } \\
\text { specified outcome }\end{array}$ \\
\hline Reduce bias & $\begin{array}{l}\text { Randomization rare } \\
\text { Lack of blinding }\end{array}$ & $\begin{array}{l}\text { Randomization } \\
\text { Double-blinded }\end{array}$ \\
\hline Standardization & $\begin{array}{l}\text { Single centre } \\
\text { Variations in practice }\end{array}$ & $\begin{array}{l}\text { Multicentre } \\
\text { Shared protocol }\end{array}$ \\
\hline Reporting & $\begin{array}{l}\text { Inconsistent } \\
\text { Incomplete } \\
\text { Difficult to synthesize }\end{array}$ & $\begin{array}{l}\text { Required } \\
\text { Comprehensive } \\
\text { Conducive to systematic review }\end{array}$ \\
\hline
\end{tabular}

There are knowledge gaps in construct validity and research methodology between preclinical models and the human condition of sepsis

remains incomplete $[8,9,12]$. Consequently, synthesis and interpretation of results becomes difficult-as has been described in preclinical systematic reviews of sepsis models $[13,14]$.

Multicentre preclinical studies serve as a promising new strategy for overcoming many of the deficiencies related to methodology and bias. These studies are defined as cooperative research formally conducted in two or more research laboratories with shared protocols and analyses [15]. Although this concept is relatively new in the preclinical environment, multicentre studies have been accepted for decades as the gold standard in clinical research [16]. Well-conducted multicentre preclinical studies maximize transparency, improve reproducibility, enhance internal and external validity (generalizability). Preclinical multicentre studies may increase the efficiency of "bench-to-bedside" translation by identifying replicable and robust findings that future development should focus on [17-19]. Indeed, high-profile multicentre preclinical studies in other fields have provided strong evidence and rationale for either 
continued or aborted investigation of novel therapeutics being considered for early phase clinical trials $[17,20]$.

\section{National Preclinical Sepsis Platform (NPSP): building on Canadian and international strengths}

Recent consensus papers by the Wiggers-Bernard Group of preclinical sepsis investigators have outlined several essential domains that should be considered the Minimum Quality Thresholds in Preclinical Sepsis Studies (MQTiPSS) [21]. The panel of international experts established high-level recommendations about model design, methodological practices, and commitment to ethical standards. The knowledge summarized in the MQTiPSS document serves as a valuable roadmap for standardization and design of future preclinical studies, and will require detailed expansion and consideration by research groups around the world.

In Canada, $\mathrm{MD}, \mathrm{PhD}$, and allied health scientists working within the Canadian Critical Care Translational Biology Group (CCСТBG, www.ccctg.ca/CCСТВG) have led efforts to study many diseases of critical illness using preclinical approaches. The CCCTBG has sponsored successful sepsis research programmes including rapid diagnostics [22], first-inhuman trials for novel therapeutics [23], and mechanisms of disease [24]. The CCCTBG has a longstanding commitment to supporting early career investigators and providing a liaison with clinical researchers in the Canadian Critical Care Trials Group (CCCTG).

In order to incorporate the recommendations of the Wiggers-Bernard Group within the Canadian context, while recognizing the need for high-quality preclinical sepsis research with increased translational impact, we established the National Preclinical Sepsis Platform (NPSP). The NPSP is a collaborative network of Canadian sepsis investigators and stakeholders, intended as a paradigm shift for preclinical sepsis research. Our overall goals are to:

1. Create a multicentre infrastructure to rigorously evaluate the pathophysiology of host response and biological heterogeneity of sepsis in a controlled preclinical environment.

2. Adopt an integrated knowledge translation approach (iKT, see next section) to identify shared research goals for preclinical sepsis research that are clinically relevant and patient-centred.

3. Generate adequately powered, high-quality preclinical data for testing safety and efficacy to accelerate the movement of novel therapeutics for sepsis into early phase clinical testing.

Here we describe our activities to date, and provide a detailed summary of the proceedings from our first in-person NPSP meeting, held on June 9, 2019 at the Prince of Wales Hotel (Niagara-on-the-Lake, Ontario, Canada). This meeting was funded by the Ontario Research Fund, the CCCTBG, as well as a Planning and Dissemination Grant from the Canadian Institutes of Health Research (Government of Canada). We believe this framework could be adopted by other groups seeking to strengthen collaborative preclinical critical care research. 


\section{Integrated knowledge translation (iKT) and patient engagement in preclinical research}

$\mathrm{iKT}$ is an approach to improve the conduct of research by "involving knowledge users as equal partners alongside researchers [25-27]". iKT is widely applied in clinical research, yet has largely been overlooked in the preclinical research environment. An iKT approach for preclinical sepsis research could engage clinical researchers to refine experimental rationale, identify clinically relevant outcomes, and help select novel therapeutics for future testing. iKT also emphasizes the collaborative role of patients and their caregivers as centrally important and contributing members of the research team (as opposed to clinical research participants). iKT in preclinical sepsis research could ensure alignment with the priorities of sepsis patients and their caregivers, and public-identified areas of interest or concern. By meaningfully engaging with these stakeholders early and throughout the research process, the results of preclinical research may be more likely to be translated into clinical practice. A conceptualized schema is found in Fig. 1.

Within the iKT framework for the NPSP, we note that while patient engagement in clinical research has gained significant momentum [28], the potential impacts and benefits of patient engagement in preclinical research (and sepsis specifically) have not been well-explored. Patient engagement strives to co-create research "with" or "by" patients, rather than "about" or "for" them, and may lead to wider dissemination of research findings, better public education of the value of research, and increased public support and funding for research endeavours [29, 30]. Moreover, patient engagement in preclinical research should be viewed as inherently positive, and aligned with the values of respect, inclusivity, and cooperation between scientists and the public, with a goal of preserving and enhancing the public trust in research. The NPSP engaged a patient partner for our first meeting and will be exploring how to strengthen this partnership as the platform is developed.

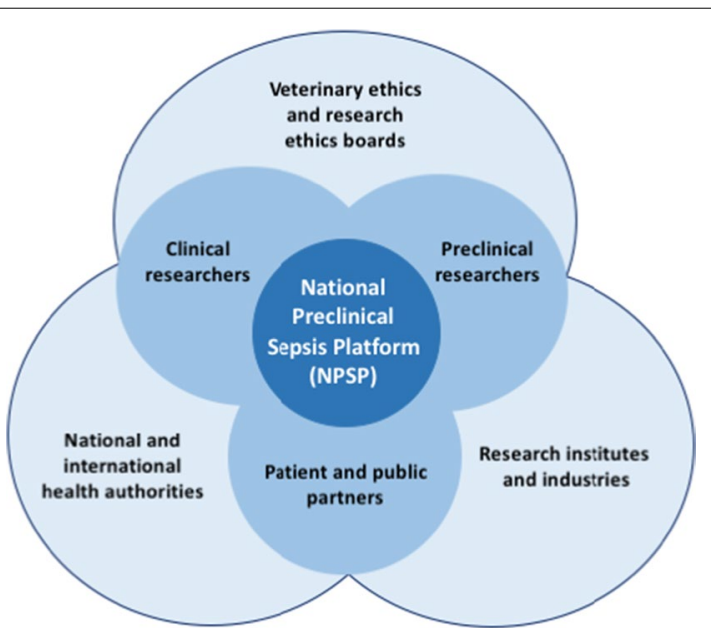

Fig. 1 An integrated knowledge translation (iKT) approach to preclinical research, as described for the National Preclinical Sepsis Platform 


\section{Pre-meeting activities}

\section{Environmental scan}

Founding laboratories of the NPSP were first identified through the CCCTBG. Further laboratories were identified through 'snowball sampling', where already identified groups suggested additional, potentially interested investigators. After initial coordination via teleconference, and preliminary presentations at national CCCTBG meetings, we secured commitment from a diverse, pan-Canadian group of preclinical sepsis investigators interested in forming the NPSP.

An environmental scan was then performed to understand the current landscape of preclinical sepsis research in Canada. A brief questionnaire was sent to principal investigators and senior highly qualified personnel from each lab (Appendix 1). Eleven laboratories shared preclinical sepsis models and experimental procedures, including granular details of current protocols (e.g. models used, animal species used, monitoring required following disease induction). Given concerns regarding intellectual property, confidentiality was assured, with details only being shared within the group of NPSP collaborators. Outcome measures routinely collected as well as specialized techniques/infrastructure were also requested. Potential barriers for multicentre standardization and harmonization (e.g. animal husbandry) were detailed carefully. These were summarized to compare and contrast current practices across the country, and identify potential areas of strength (e.g. shared models/outcomes) and other areas that will require efforts to harmonize (e.g. differing analgesia protocols required by local animal care services). Individual lab details and the summary were then deposited in a shared online repository to continue building the NPSP collaboration.

\section{Identification of additional stakeholders}

The majority of stakeholders were preclinical sepsis investigators, members of the CCCTBG, and research assistants and trainees directly performing preclinical sepsis experiments. We specifically recruited additional stakeholders from outside this community to participate in the NPSP, including clinical researchers, laboratory animal veterinarians, a patient partner, and clinical research coordinators. We engaged knowledge translation scientists (KMF, JP) to effectively operationalize our efforts. We believe these strategies will strengthen linkages between preclinical and clinical researchers during initial study design, and create formal mechanisms for preclinical results to move rapidly into clinical research. Representation from patient partners was viewed as particularly important to ensure patient and caregiver perspectives were incorporated throughout the NPSP.

\section{Meeting summary}

The itinerary from the first in-person NPSP meeting can be found in Appendix 2. The goal of the first in-person NPSP meeting was to establish this unique national collaboration and to build consensus on immediate next steps towards implementation of the platform. A participant list for the NPSP meeting can be found in Appendix 3. The total number of participants was 29 of which 10 (35\%) were highly qualified personnel (a standard term in Canada used to identify trainees and research personnel [31]). 
Nine cities from 5 provinces were represented and a total of 10 independent lab groups attended the meeting (Fig. 2). An additional 15 participants were invited but could not attend, giving their regrets. These additional participants contributed to pre- and postmeeting activities and planning.

\section{Overview of multicentre preclinical studies: results of a systematic review and interview study}

A brief overview of the concept and current landscape of multicenter preclinical studies was summarized by an ongoing systematic review and interview study being conducted by several participants (VH, MML, CL) [19]. Based on a systematic search, only 13 multicentre preclinical studies were published from 1985 to 2015, studying diseases in six different areas (none in sepsis). Multicentre studies included in the systematic review were largely performed to confirm preclinical findings prior to testing interventions in humans. As described above, benefits of these studies included increased external validity (i.e. generalizability of findings between laboratories), adequately powered studies, and extensive quality control (e.g. routine, regular oversight). Importantly, interviews of scientists who conducted these studies demonstrated that these were highly collaborative endeavours that benefited from engagement and transparency of all stakeholders involved. Additionally, as noted by the multicentre investigators, these studies were difficult to fund given their novelty and cost, and required greater time and resources than single-centre preclinical research. An important feature of preclinical multicenter projects, and a critical consideration when designing these studies, was the common protocol across participating centres. Multicentre studies were either fully harmonized (identical protocol implementation across laboratories) or triangulated (deliberate between-lab variations in experimental design) depending on the overall objective and scientific hypothesis being tested [19]. Triangulation was particularly beneficial when more than one animal model was tested between centres (i.e. since no single model can recapitulate all features of human pathophysiology).

\section{Animal ethics and veterinary considerations}

This section of the meeting was presented by the director of standards from the Canadian Council for Animal Care (CCAC), the national organization that provides ethical guidance for animal care committees that oversee preclinical research at their respective institutions. CCAC standards (guidelines and policies) are grounded in the 3Rs tenet of replacement, reduction and refinement of animal use. For preclinical protocols with the potential for animals to experience severe suffering (including sepsis models) there is a requirement for more careful ethical review of the protocol, and for more attention to the animals during the course of the study; ultimately, consistent animal care and treatment are essential for the production of robust scientific results. Animal care committees are required to consider the experiences of research animals in relation to the potential benefits to be accrued from the work, and researchers are encouraged to work with the laboratory animal veterinarians at their respective institutions to develop strategies to address these issues. This places an onus on researchers and veterinarians alike to ensure that the outcomes from the studies are reproducible and translatable. 


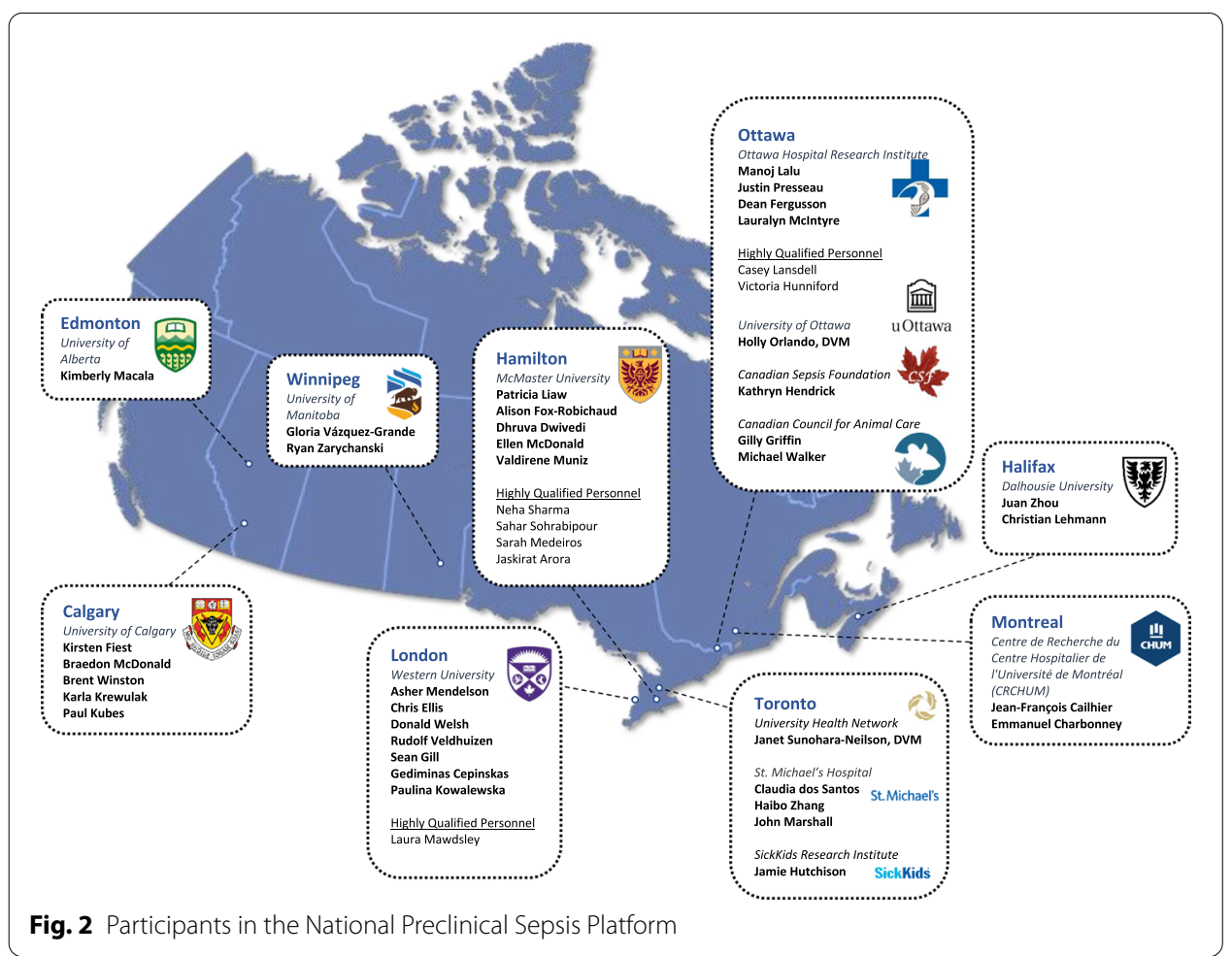

The NPSP provides an opportunity to harmonize protocols between laboratories, and resolve some of the ethical challenges with preclinical sepsis research (for example, defining appropriate endpoints that permit the collection of relevant data, but limit pain and distress for the animals, and determining when analgesia can be provided). While logistical hurdles are inevitable when coordinating between institutions (including the animal care committee reviews), the comprehensive and measured approach of the NPSP is conducive to the reduction and refinement of animal use, thus limiting the wastage of animal lives and ensuring that the data fully contributes to the research record.

\section{Small group discussion}

The details of the environmental scans from each participating laboratory were summarized and presented to the group as a whole. The group then reflected on the similarities and differences between preclinical sepsis models across the country, particularly regarding the severity of sepsis models (lethal vs sub-lethal), co-administration of common therapies (fluids, antibiotics), and duration of study. Subsequently, participants were separated into four small groups. Each group rotated through four discussion topics: (1) the objectives of the NPSP, (2) the sepsis models that the NPSP should pursue, (3) methodology of NPSP experiments, and (4) outcomes that should be studied. This was followed with full-group discussion to summarize small group discussions. Conversations were facilitated by meeting organizers at each table and transcribed in real-time by trainee volunteers. 


\section{NPSP objectives}

Two broad categories of objectives for the NPSP were identified: (a) understand basic mechanisms of sepsis pathophysiology, and (b) assess novel therapeutics for sepsis [32]. Within the therapeutic category, opportunities also exist to study the effect of multiple co-interventions and refinement of conventional therapies. Given how the themes are inter-related, cultivating these two objectives in parallel was viewed as a positive strategy. In addition, the biological variability described by pathophysiology studies can identify sepsis subclasses with common biological features; this data can be used for prognostic or predictive enrichment in clinical trial design [33] or with further testing of novel therapeutics in the preclinical setting. Participants noted that the NPSP can serve as a quality assurance checkpoint for research before considering clinical testing in humans. This may require single-centre research to be presented to the NPSP and replicated across the platform in a multicentre fashion.

\section{Sepsis models}

Participants discussed various models commonly used by preclinical sepsis scientists in Canada; universally these were rat and murine models, with merits and drawbacks for both species. Advantages for murine models include shorter reproductive cycles, economical housing/maintenance costs, and availability of genetically modified strains. Conversely, the use of invasive haemodynamic monitors (e.g. blood pressure) and mechanical ventilation is possible in rats, but more technically challenging in mice. The integration of predisposing conditions (e.g. diabetes, age, biological sex) into the sepsis models was viewed as particularly relevant for clinical translation. These co-morbid animals would reflect patients at increased risk for developing sepsis and for poor sepsis outcomes.

In terms of model specifics, participants recognized that a "gold standard" model for sepsis does not exist, and all models have benefits and drawbacks; the group concurred with MQTiPSS that endotoxemia was not representative of clinical sepsis. Discrepancy was noted between preclinical sepsis models where the time of infectious insult is known, and clinical sepsis where presentation to the emergency department can occur at variable time points in the disease process.

Overall, participants agreed that minimizing surgical variability by selecting less challenging and more technically simple sepsis models was a priority for the platform. The value of investigating models outside of traditional abdominal Gram-negative sepsis was recognized. Participants further agreed that efforts should be made to develop/include at least two sepsis models for the platform. Finally, although the participants noted the existence of robust long-term (e.g. up to 28 days) preclinical models of sepsis [34, 35], there was agreement that this type of model would require intensive personnel support and incur much higher costs. Given that acute sepsis models $(<24 \mathrm{~h})$ are much more common, this leads to under-representation of the late phase of the disease in preclinical experimentation, despite its significant contribution to human sepsis deaths [36].

The "PIRO" model (predisposition, insult, response, organ dysfunction) was accepted as an overall experimental framework for the platform. PIRO was first introduced as a scoring system for acute illness in clinical settings [37]. By applying PIRO to preclinical sepsis research, we link our experimental design with clinical and population health 
researchers using a common language. This framework also provides a consistent structure and reproducible design for future studies, including the potential evaluation of novel therapeutic interventions.

\section{Methodology to increase reproducibility and reduce bias}

The key tenets of improving internal validity/methodological rigour were explained (e.g. blinding, randomization, sample size calculation), and participants discussed how to incorporate them into the NPSP. The concept of protocol harmonization was discussed; overall, participants agreed that full harmonization of basic protocols would initially yield greater advantages versus a 'triangulation' approach (where a common intervention is tested but models, protocols, and outcomes remain unique between labs). Harmonization would also ensure that processes that are implicit in each participating laboratory are made explicit, and that previously unaccounted variation could be considered. While some heterogeneity between labs may be addressed with technical training sessions, other heterogeneity between centres (e.g. housing conditions, commensal flora) would still remain. These variations were thought to be potentially beneficial to assess generalizability of findings to the clinical setting where heterogeneity is common. Standardization could be facilitated for centres with varying levels of technical expertise using detailed and descriptive standard operating procedures; video training modules and in-person demonstrations were both mentioned. Participants recognize that even with efforts to achieve total standardization, variability will persist due to the inherent biological heterogeneity of sepsis. By controlling for variability as much as possible, however, the platform will help determine the impact of this biological heterogeneity on sepsis outcomes (e.g. by stratifying according to confounders that cannot be controlled).

Validation of models and quality assurance across multiple laboratories was recognized as essential to ensure reproducibility and generalizability of results. The participants discussed potential methods for this to be achieved, including use of a preclinical scoring system to assess disease severity that is standardized and clinically relevant [38]. In order to address issues of bias that are very common for preclinical laboratory studies [12], methods to increase internal validity of studies were discussed. For instance, selection bias can be minimized with a priori inclusion/exclusion criteria that ascertain whether the animals have achieved sepsis (e.g. scoring system, biomarkers, bacterial load). In addition, sample sizes should be calculated a priori based on current literature and data from pilot studies to adequately power NPSP studies to detect differences between experimental groups. Finaly, an independent, arms-length committee for oversight and quality assurance was also suggested, similar to a Drug and Safety Monitoring Committee in clinical trials. This committee would review proposed protocols and interventions, and provide both scientific and quality control advice for NPSP investigators.

Participants agreed that sharing of biological specimens for centralized analysis would be optimal, but that it would require many additional logistical and cost considerations. Coordinating animal ethics approval across multiple centres was seen as a potential barrier for many investigators but the veterinarian stakeholders believed it could be addressed with appropriate communication and coordination between centre veterinarians. Participants noted that study protocols should be transparent, 
registered (e.g. www.preclinicaltrials.eu) [39], and potentially published ahead of time. The value of publishing negative results from the platform was also recognized, as these could inform future study designs.

\section{Outcomes for evaluation}

It was agreed by participants that the NPSP should evaluate clinically relevant outcomes, but also capture the fundamental pathophysiology of sepsis (i.e. biological outcomes). Efforts should be made to align the NPSP with outcomes that matter to patient partners and caregivers; this relates particularly with long-term outcomes for mobility and cognitive function. Ethical considerations were raised for mortality outcomes in animal models of sepsis [32] and the need to identify appropriate "mortality surrogates" and humane endpoints that can be used to correlate with meaningful clinical outcomes [40]. Biological outcomes should address the scope of sepsis including immunology, coagulation, microcirculation, and cellular metabolism. NPSP participants agreed that there should be a basic panel of outcomes measured across all sites, as well as site-specific outcomes based on nationally recognized expertise. Multiple organ systems should be evaluated with outcomes that can best align with clinical research; functional outcomes may be challenging to evaluate in the preclinical setting given that they often represent complex processes (e.g. cognition, mobility). In addition, given the paucity of safety data in published preclinical sepsis studies, it was agreed that studies for novel therapeutics should include a priori defined safety outcomes in addition to efficacy data.

\section{Keynote address: Dr. Marcin Osuchowski, MQTiPSS, Wiggers-Bernard Group}

Dr. Osuchowski connected via videoconference to the NPSP meeting, to deliver a keynote address on the design and creation of the MQTiPSS recommendations. Insights were shared regarding logistical considerations for organizing a large team of preclinical researchers, as well as the dialogue and consensus approaches that were adopted for the project.

Dr. Osuchowski reported the 10th Wiggers-Bernard Conference Initiative on Preclinical Modeling in Sepsis (www.wiggers-bernard.org) has launched an international multicentre preclinical sepsis trial; the details and logistics were discussed at the 2019 Wiggers-Bernard Meeting (Chania, Crete, Greece). Dr. Osuchowski commended the NPSP participants for undertaking a similar initiative in Canada, and all participants expressed a desire for ongoing communication and shared discussions as these projects continue to evolve.

\section{Patient engagement at the NPSP}

Although preclinical researchers and patient partners shared a common goal and purpose (i.e. improving treatment for sepsis patients), NPSP participants felt that it was unclear how patient partner skills and lived experiences could be successfully integrated into this laboratory-focused endeavour. Common language and frame of reference was lacking, which prevented a substantive discussion about preclinical research collaboration. This was identified as a key barrier despite the positive attitude and efforts by participants and our patient partner. Accordingly, we have undertaken a critical 
examination of this issue with a scoping review for effective strategies to achieve successful patient-preclinical engagement. In addition, it was felt that having multiple patient partners engaged in future NPSP meetings would improve representation and better reflect a diversity of patient and caregiver perspectives.

\section{Future directions}

The NPSP brings together a diverse set of stakeholders from across Canada and represents an innovative and exciting resource for preclinical sepsis research. Through foundational discussions at our first in-person meeting, participants were able to achieve consensus on the overall objective (i.e. to undertake multicentre preclinical studies evaluating the pathophysiology of sepsis), and identified a number of specific issues that require more planning (e.g. protocol harmonization, research questions).

Further discussions are needed to clarify data management procedures and ethics approval between centres, which will be a priority for the upcoming success of this platform. Moreover, participants noted that external funding opportunities will be needed to ensure the sustainability of the platform. Participants will be encouraged to develop lines of research that can leverage the NPSP infrastructure while also building on the unique strengths and expertise of individual investigators.

There are short-term and medium-term objectives for the NPSP that we plan to accomplish. In support of these endeavours, Sepsis Canada (an interdisciplinary network dedicated to sepsis research) was recently funded by the Canadian Institutes of Health Research. This network will invest in infrastructure required for NPSP operations. Since the meeting, we have continued to form consensus regarding details of the animal models and outcomes for evaluation. Moreover, scientific hypotheses within the PIRO framework (e.g. effect of predisposing conditions on sepsis outcomes) are being elaborated with preclinical systematic reviews to assist with study design. Finally, we have started to plan the first series of pilot experiments that will serve to demonstrate the feasibility of this platform, and allow us to refine the logistics needed for coordinating a multicentre preclinical platform.

In conclusion, we hope that details outlined by these proceedings will serve as a template and inspiration for other investigators who are seeking to establish similar collaborative projects. The creation of high-quality preclinical research should be viewed as a priority for the sepsis research community, and multicentre preclinical research can help maximize the translational impact of preclinical findings. The success of these endeavours will require dedication and teamwork. We are confident that the NPSP will elucidate new insights into sepsis pathogenesis, and accelerate the development of improved treatment strategies for patients with sepsis. 


\section{Appendix 1. Questions for initial environmental scan of preclinical sepsis laboratories}

PI and institute:

Variable

Experimental model

Name of model

Details of disease induction method

Timing of sacrifice (what is the latest timepoint following disease induction)

Analgesia (if any, type, dose and timing)

Antibiotics (if any, type, dose, and timing)

Fluids (if any, type, dose, and timing)

Physiological monitoring details (e.g. temperature, heart rate, etc., and materials used)

Physiological monitoring frequency (e.g. every hour, specific timepoints)

Method of sacrifice (e.g. pentobarbital overdose)

Outcomes you have used/reported on with this model (provide timing and general method used (e.g. plasma cytokines; 3, 6, 12, 24 h; ELISA)

Humane endpoints (details from animal care)

Animal

Species

Background

Wild type or mutant (+ type of variation)

Vendor

Sex

Age

Average \# of animals per experiment

\# animals per cage

Animal ID (how do you label/ID animals; ear notch/tags/tail markings)

Location of housing (e.g. conventional, biohazard, stepdown)

Husbandry

Diet

Light cycle

Health status of rooms

Noise level/traffic of rooms

Bedding type

Water treatment (e.g. acidified)

Type of cage

Enrichment (e.g. cardboard house)

Frequency of cage change

Timing of cage change relative to the intervention

Animal care settings 
Variable

Room temperature

Relative humidity

Air changes per hour

Publications

Any publications that highlight your use of this model?

Additional comments

\section{Appendix 2. National Preclinical Sepsis Platform-meeting agenda}

\begin{tabular}{|c|c|c|}
\hline Time & Topic & Speaker \\
\hline 10:45-11:00 & Registration, Sign-In & \\
\hline 11:00-11:30 & Introductions, overview of day, ice-breaker & Asher Mendelson \\
\hline 11:30-11:45 & Why should we conduct preclinical multicenter studies? & Manoj Lalu \\
\hline 11:45-12:00 & Barriers and facilitators to preclinical multicenter studies & Victoria Hunniford \\
\hline 12:00-12:45 & $\begin{array}{l}\text { Applying a framework of integrated knowledge transla- } \\
\text { tion (iKT) to preclinical research }\end{array}$ & Kirsten Fiest \\
\hline 12:45-13:15 & $\begin{array}{l}\text { Animal ethics and collaboration with laboratory animal } \\
\text { veterinarians }\end{array}$ & Gilly Griffin and Janet Sunohara-Neilson \\
\hline 13:15-13:45 & Lunch & \\
\hline $13: 45-14: 45$ & $\begin{array}{l}\text { Review of environmental scan: what is the landscape of } \\
\text { Canadian preclinical sepsis research? }\end{array}$ & Manoj Lalu \\
\hline $14: 45-15: 30$ & $\begin{array}{l}\text { Keynote Address: MQTiPSS guidelines and beyond: a } \\
\text { personal insight on how to improve the quality of } \\
\text { sepsis modeling }\end{array}$ & Marcin Osuchowski \\
\hline 15:30-15:45 & Break for refreshments and group photo & \\
\hline 15:45-17:05 & $\begin{array}{l}\text { Building Consensus on a Canadian Preclinical Sepsis } \\
\text { Platform } \\
\text { Table } 1 \text { Sepsis Models: Which models are feasible and } \\
\text { clinically relevant? } \\
\text { Table } 2 \text { Purpose of NPSP: What studies should the plat- } \\
\text { form undertake (e.g. therapies, biomarkers, pathophysi- } \\
\text { ology)? } \\
\text { Table } 3 \text { Methodology: What methods/logistics considera- } \\
\text { tions are needed for the platform? } \\
\text { Table } 4 \text { Outcomes: What outcomes are important for } \\
\text { translation to patients? }\end{array}$ & $\begin{array}{l}\text { Facilitator: Alison Fox-Robichaud } \\
\text { Everyone will participate in } 20 \text { min } \\
\text { discussions per table, then rotate } \\
\text { Trainees are notetakers }\end{array}$ \\
\hline 17:05-17:20 & Break & \\
\hline $17: 20-18: 40$ & Tables report back on group discussions & All \\
\hline 18:40-19:00 & $\begin{array}{l}\text { Next steps, Canadian Sepsis Network proposal discus- } \\
\text { sion, and closing remarks }\end{array}$ & $\begin{array}{l}\text { Manoj Lalu, Asher Mendelson and } \\
\text { Alison Fox-Robichaud }\end{array}$ \\
\hline 19:30 & $\begin{array}{l}\text { Networking Dinner: Noble Restaurant, Prince of Wales } \\
\text { Hotel }\end{array}$ & \\
\hline
\end{tabular}




\section{Appendix 3. List of participants at the National Preclinical Sepsis Platform meeting. There were 29 people in attendance and 15 gave their regrets but contributed through teleconferences and other communication pre- and post-meeting. *Organizing committee}

\begin{tabular}{|c|c|}
\hline Name & Primary affiliations \\
\hline Alison Fox-Robichaud* & $\begin{array}{l}\text { Staff Physician, Department of Medicine, Division of Critical Care, Hamilton Health Sci- } \\
\text { ences, Hamilton, Ontario } \\
\text { Scientist, Department of Medicine and Thrombosis and Atherosclerosis Research Insti- } \\
\text { tute, McMaster University, Hamilton, Ontario }\end{array}$ \\
\hline Asher Mendelson* & $\begin{array}{l}\text { Staff Physician, Intensive Care Unit, St. Mary's General Hospital, Kitchener, Ontario } \\
\text { Adjunct Scientist, Centre for Critical Illness Research, Lawson Health Research Institute, } \\
\text { London, Ontario } \\
\text { Ph.D. Candidate, Department of Medical Biophysics, Schulich School of Medicine \& } \\
\text { Dentistry, University of Western Ontario, London, Ontario }\end{array}$ \\
\hline Casey Lansdell* & $\begin{array}{l}\text { Research Assistant, Department of Regenerative Medicine, Ottawa Hospital Research } \\
\text { Institute, Ottawa, Ontario }\end{array}$ \\
\hline Chris Ellis & $\begin{array}{l}\text { Scientist, Department of Medical Biophysics, Schulich School of Medicine \& Dentistry } \\
\text { and Robarts Research Institute, University of Western Ontario, London, Ontario }\end{array}$ \\
\hline Christian Lehmann & $\begin{array}{l}\text { Scientist, Department of Anesthesia, Pain Management \& Perioperative Medicine, } \\
\text { Dalhousie University, Halifax, Nova Scotia }\end{array}$ \\
\hline Claudia dos Santos & $\begin{array}{l}\text { Staff Physician, Department of Medicine, Division of Respirology, St. Michael's Hospital, } \\
\text { Toronto, Ontario } \\
\text { Scientist, Keenan Research Centre for Biomedical Science, St. Michael's Hospital, } \\
\text { Toronto, Ontario }\end{array}$ \\
\hline Dhruva Dwivedi & $\begin{array}{l}\text { Postdoctoral Fellow, Department of Medicine, Division of Hematology and Thrombo- } \\
\text { embolism, McMaster University, Hamilton, Ontario } \\
\text { Research Associate, Thrombosis and Atherosclerosis Research Institute, McMaster } \\
\text { University, Hamilton, Ontario }\end{array}$ \\
\hline Donald Welsh & $\begin{array}{l}\text { Scientist, Department of Physiology and Pharmacology, Schulich School of Medicine } \\
\text { \& Dentistry and Robarts Research Institute, University of Western Ontario, London, } \\
\text { Ontario }\end{array}$ \\
\hline Ellen McDonald & $\begin{array}{l}\text { Research Coordinator, Department of Medicine, McMaster University, Hamilton, Ontario } \\
\text { and the Thrombosis and Atherosclerosis Research Institute, Hamilton, Ontario }\end{array}$ \\
\hline Gilly Griffin & $\begin{array}{l}\text { Director of Standards, Standards Setting and Maintenance unit, Canadian Council on } \\
\text { Animal Care, Ottawa, Ontario }\end{array}$ \\
\hline Gloria Vázquez-Grande & $\begin{array}{l}\text { Critical Care External Clinician Fellow, Intensive Care Unit, Winnipeg Regional Health } \\
\text { Authority, Winnipeg, Manitoba } \\
\text { Ph.D. Candidate, Department of Medical Microbiology and Infectious Diseases, Univer- } \\
\text { sity of Manitoba, Winnipeg, Manitoba }\end{array}$ \\
\hline Jamie Hutchison & $\begin{array}{l}\text { Staff Physician, Department of Critical Care Medicine, The Hospital for Sick Children, } \\
\text { Toronto, Ontario } \\
\text { Senior Scientist, Neuroscience and Mental Health Research Program, SickKids Research } \\
\text { Institute, Toronto, Ontario }\end{array}$ \\
\hline Janet Sunohara-Neilson & Clinical Veterinarian, University Health Network, Toronto, Ontario \\
\hline Jean-François Cailhier & $\begin{array}{l}\text { Staff Physician, Department of Medicine, Institut du cancer de Montréal, Montreal, } \\
\text { Quebec } \\
\text { Senior Scientist, Department of Medicine, Centre de Recherche du Centre Hospitalier } \\
\text { de I'Université de Montréal (CRCHUM), Montreal, Quebec }\end{array}$ \\
\hline Juan Zhou & $\begin{array}{l}\text { Scientist, Department of Anesthesia, Pain Management \& Perioperative Medicine, } \\
\text { Dalhousie University, Halifax, Nova Scotia }\end{array}$ \\
\hline Kathryn Hendrick & $\begin{array}{l}\text { Patient Partner Advocate for improved sepsis management, Ottawa, Ontario } \\
\text { Volunteer Communications Director, Global Sepsis Alliance, Canada Sector, Toronto, } \\
\text { Ontario } \\
\text { Canada Board Member, Canadian Sepsis Foundation, Markham, Ontario }\end{array}$ \\
\hline Kimberly Macala & $\begin{array}{l}\text { Staff Physician, Division of Critical Care, Royal Alexandra Hospital, Edmonton, Alberta } \\
\text { Scientist, Department of Critical Care Medicine, University of Alberta, Edmonton, } \\
\text { Alberta }\end{array}$ \\
\hline
\end{tabular}




\begin{tabular}{|c|c|}
\hline Name & Primary affiliations \\
\hline Kirsten Fiest & $\begin{array}{l}\text { Scientist, Department of Critical Care Medicine, Community Health Sciences and } \\
\text { Psychiatry, University of Calgary, Calgary, Alberta }\end{array}$ \\
\hline Laura Mawdsley & $\begin{array}{l}\text { M.Sc. Candidate, Department of Medical Biophysics, Schulich School of Medicine \& } \\
\text { Dentistry, University of Western Ontario, London, Ontario }\end{array}$ \\
\hline Manoj Lalu* & $\begin{array}{l}\text { Staff Physician, Department of Anesthesiology and Pain Medicine, The Ottawa Hospital, } \\
\text { Ottawa, Ontario } \\
\text { Associate Scientist, Regenerative Medicine and Clinical Epidemiology Programs, The } \\
\text { Ottawa Hospital Research Institute, Ottawa, Ontario }\end{array}$ \\
\hline Michael Walker & Senior Research Analyst, Canadian Council on Animal Care, Ottawa, Ontario \\
\hline Neha Sharma & $\begin{array}{l}\text { Ph.D. Candidate, Department of Medical Sciences, McMaster University, Hamilton, } \\
\text { Ontario and the Thrombosis and Atherosclerosis Research Institute, Hamilton, Ontario }\end{array}$ \\
\hline Patricia Liaw* & $\begin{array}{l}\text { Scientist, Department of Medicine, McMaster University, Hamilton, Ontario and the } \\
\text { Thrombosis and Atherosclerosis Research Institute, Hamilton, Ontario }\end{array}$ \\
\hline Rudolf Veldhuizen & $\begin{array}{l}\text { Scientist, Critical IIIness Research Program, Lawson Health Research Institute and } \\
\text { Departments of Medicine and Physiology \& Pharmacology, Schulich School of Medi- } \\
\text { cine \& Dentistry, University of Western Ontario, London, Ontario }\end{array}$ \\
\hline Sahar Sohrabipour & $\begin{array}{l}\text { M.Sc. Candidate, Department of Medical Sciences, McMaster University, Hamilton, } \\
\text { Ontario and the Thrombosis and Atherosclerosis Research Institute, Hamilton, Ontario }\end{array}$ \\
\hline Sarah Medeiros & $\begin{array}{l}\text { Ph.D. Candidate, Department of Medical Sciences, McMaster University, Hamilton, } \\
\text { Ontario and the Thrombosis and Atherosclerosis Research Institute, Hamilton, Ontario }\end{array}$ \\
\hline Sean E Gill & $\begin{array}{l}\text { Scientist, Critical IIIness Research Program, Lawson Health Research Institute and } \\
\text { Departments of Medicine and Physiology \& Pharmacology, Schulich School of Medi- } \\
\text { cine \& Dentistry, University of Western Ontario, London, Ontario }\end{array}$ \\
\hline Valdirene S Muniz & $\begin{array}{l}\text { Postdoctoral Fellow, Department of Medical Sciences, McMaster University, Hamilton, } \\
\text { Ontario and the Thrombosis and Atherosclerosis Research Institute, Hamilton, Ontario }\end{array}$ \\
\hline Victoria Hunniford & M.Sc. Candidate, Telfer School of Management, University of Ottawa, Ottawa, Ontario \\
\hline \multicolumn{2}{|l|}{ Regrets: } \\
\hline Braedon McDonald & $\begin{array}{l}\text { Staff Physician, Foothills Medical Centre, Rockyview General Hospital and South Health } \\
\text { Campus, Calgary, Alberta } \\
\text { Scientist, Snyder Institute for Chronic Diseases and International Microbiome Centre, } \\
\text { Cumming School of Medicine, University of Calgary, Calgary, Alberta }\end{array}$ \\
\hline Brent Winston & $\begin{array}{l}\text { Scientist, Immunology Research Group and Airway Inflammation Research Group, } \\
\text { Snyder Institute for Chronic Diseases, Cumming School of Medicine, University of } \\
\text { Calgary, Calgary, Alberta }\end{array}$ \\
\hline Dean Fergusson & $\begin{array}{l}\text { Director and Senior Scientist, Clinical Epidemiology Program, Ottawa Hospital Research } \\
\text { Institute, Ottawa, Ontario }\end{array}$ \\
\hline Emmanuel Charbonney & $\begin{array}{l}\text { Staff Physician, Intensive Care Unit, Département de Médecine, Université de Montréal, } \\
\text { Montreal, Quebec } \\
\text { Scientist, Centre de Recherche du Centre Hospitalier de l'Université de Montréal, } \\
\text { Montreal, Quebec }\end{array}$ \\
\hline Gediminas Cepinskas & $\begin{array}{l}\text { Director and Scientist, Centre for Critical IIIness Research, Lawson Health Research Insti- } \\
\text { tute and Department of Medical Biophysics, Schulich School of Medicine \& Dentistry, } \\
\text { University of Western Ontario, London, Ontario }\end{array}$ \\
\hline Haibo Zhang & $\begin{array}{l}\text { Staff Physician, Interdepartmental Division of Critical Care Medicine; Departments of } \\
\text { Anesthesia and Physiology, University of Toronto, Ontario } \\
\text { Scientist, Keenan Research Centre for Biomedical Science, Department of Physiology, } \\
\text { St. Michael's Hospital, Toronto, Ontario }\end{array}$ \\
\hline Holly Orlando & $\begin{array}{l}\text { Director and Veterinarian, Animal Care and Veterinary Service, University of Ottawa, } \\
\text { Ottawa, Ontario }\end{array}$ \\
\hline John Marshall & $\begin{array}{l}\text { Staff Physician, Departments of Surgery and Critical Care Medicine, St. Michael's Hospi- } \\
\text { tal, Toronto, Ontario } \\
\text { Co-Director and Senior Scientist, Critical IIIness and Injury Research Centre, Keenan } \\
\text { Research Centre for Biomedical Science, St. Michael's Hospital, Toronto, Ontario }\end{array}$ \\
\hline Justin Presseau & $\begin{array}{l}\text { Scientist, Clinical Epidemiology Program, Ottawa Hospital Research Institute, Ottawa, } \\
\text { Ontario }\end{array}$ \\
\hline Karla Krewulak & $\begin{array}{l}\text { Senior Research Associate, Department of Critical Care Medicine, University of Calgary, } \\
\text { Calgary, Alberta }\end{array}$ \\
\hline Lauralyn McIntyre* & $\begin{array}{l}\text { Staff Physician, Department of Medicine, Division of Critical Care, The Ottawa Hospital, } \\
\text { Ottawa, Ontario } \\
\text { Senior Scientist, The Ottawa Hospital Research Institute, Ottawa, Ontario }\end{array}$ \\
\hline
\end{tabular}




\begin{tabular}{|c|c|}
\hline Name & Primary affiliations \\
\hline Paul Kubes & $\begin{array}{l}\text { Scientist, Department of Physiology and Pharmacology, Immunology Research Group } \\
\text { and Snyder Institute for Chronic Diseases, Cumming School of Medicine, University of } \\
\text { Calgary, Calgary, Alberta }\end{array}$ \\
\hline Paulina Kowalewska & $\begin{array}{l}\text { Postdoctoral Fellow, Robarts Research Institute, University of Western Ontario, London, } \\
\text { Ontario }\end{array}$ \\
\hline Ryan Zarychanski & $\begin{array}{l}\text { Staff Physician, Department of Internal Medicine, University of Manitoba, Winnipeg, } \\
\text { Manitoba } \\
\text { Senior Scientist, Department of Medicine, Sections of Critical Care and of Hematology/ } \\
\text { Medical Oncology, Research Institute of Oncology and Hematology, University of } \\
\text { Manitoba, Winnipeg, Manitoba }\end{array}$ \\
\hline
\end{tabular}

\section{Abbreviations}

CCAC: Canadian Council for Animal Care; CCCTBG: Canadian Critical Care Translational Biology Group; iKT: Integrated knowledge translation; MQTiPSS: Minimum quality thresholds in preclinical sepsis studies; NPSP: National Preclinical Sepsis Platform; PIRO: Predisposition, insult, response, organ dysfunction.

\section{Acknowledgements}

MML is supported by The Ottawa Hospital Anesthesia Alternate Funds Association and holds a University of Ottawa Junior Research Chair in Innovative Translational Research.

\section{Authors' contributions}

Conceptualization: MML, AAM, PL, PK, AFR. Data curation: AAM, CL, MML. Funding acquisition: MML, AAM, AFR. Project administration: CL. Visualization: AAM, MML, CL, GF. Writing—original draft: AAM, MML, JS, KF, VH. Writing—review and editing: all authors. All authors read and approved the final manuscript.

\section{Funding}

Planning and Dissemination Grant, Canadian Institutes of Health Research and Solutions for Cardio-pulmonary Organ Repair and Regeneration, Ontario Research Fund.

\section{Availability of data and materials}

Not applicable.

\section{Ethics approval and consent to participate}

Not applicable.

\section{Consent for publication}

Not applicable.

\section{Competing interests}

The authors declare that they have no competing interests.

\section{Author details}

${ }^{1}$ Department of Medical Biophysics, Schulich School of Medicine and Dentistry, University of Western Ontario, London, ON, Canada. ${ }^{2}$ Centre for Critical IIIness Research, Lawson Health Research Institute, London, ON, Canada. ${ }^{3}$ Regenerative Medicine Program, Ottawa Hospital Research Institute, Ottawa, ON, Canada. ${ }^{4}$ Department of Medicine, McMaster University, Hamilton, ON, Canada. ${ }^{5}$ Thrombosis and Atherosclerosis Research Institute, Hamilton, ON, Canada. ${ }^{6}$ Department of Medical Sciences, McMaster University, Hamilton, ON, Canada. ${ }^{7}$ Centre de Recherche du Centre Hospitalier de l'Université de Montréal, Montreal, QC, Canada. ${ }^{8}$ Département de Médecine, Université de Montréal, Montreal, QC, Canada. ${ }^{9}$ Keenan Research Centre for Biomedical Science, Unity Health Toronto, Toronto, ON, Canada. ${ }^{10}$ Interdepartmental Division of Critical Care Medicine, University of Toronto, Toronto, ON, Canada. ${ }^{11}$ Department of Medicine, University of Toronto, Toronto, ON, Canada. ${ }^{12}$ Robarts Research Institute, University of Western Ontario, London, ON, Canada. ${ }^{13}$ Clinical Epidemiology Program, Ottawa Hospital Research Institute, Ottawa, ON, Canada. ${ }^{14}$ Department of Critical Care Medicine, Cumming School of Medicine, University of Calgary, Calgary, AB, Canada. ${ }^{15}$ Department of Medicine, Schulich School of Medicine and Dentistry, University of Western Ontario, London, ON, Canada. ${ }^{16}$ Department of Communications, Global Sepsis Alliance, Canada Sector, Toronto, ON, Canada. ${ }^{17}$ Department of Anesthesia, Pain Management and Perioperative Medicine, Dalhousie University, Halifax, NS, Canada. ${ }^{18}$ Department of Critical Care Medicine, Royal Alexandra Hospital, University of Alberta, Edmonton, AB, Canada. ${ }^{19}$ Department of Surgery, University of Toronto, Toronto, ON, Canada. ${ }^{20}$ Snyder Institute for Chronic Diseases, Cumming School of Medicine, University of Calgary, Calgary, AB, Canada. ${ }^{21}$ Ludwig Boltzmann Institute for Experimental and Clinical Traumatology, Vienna, Austria. ${ }^{22}$ School of Epidemiology and Public Health, University of Ottawa, Ottawa, ON, Canada. ${ }^{23}$ Animal Resources Centre, University Health Network, Toronto, ON, Canada. ${ }^{24}$ Department of Internal Medicine, Section of Critical Care, University of Manitoba, Winnipeg, MB, Canada. ${ }^{25}$ Department of Medical Microbiology and Infectious Diseases, University of Manitoba, Winnipeg, MB, Canada. ${ }^{26}$ Department of Medicine, University of Calgary, Calgary, AB, Canada. ${ }^{27}$ Department of Internal Medicine, Section of Hematology/Medical Oncology, University of Manitoba, Winnipeg, MB, Canada. ${ }^{28}$ Interdepartmental Division of Critical Care Medicine, Department of Anesthesia, University of Toronto, Toronto, ON, Canada. ${ }^{29}$ Department of Anesthesiology and Pain Medicine, The Ottawa Hospital, 501 Smyth Road, PO Box 201B, Ottawa, ON K1H 8L6, Canada. ${ }^{30}$ Department of Physiology and Pharmacology, Schulich School of Medicine and Dentistry, University of Western Ontario, London, ON, Canada. ${ }^{31}$ Department of Critical Care Medicine, University of Toronto, Toronto, ON, Canada. 32 Department of Biochemistry and Molecular Biology, University of Calgary, Calgary, AB, Canada. ${ }^{33}$ Interdepartmental Division of Critical Care Medicine, Department of Physiology, University of Toronto, Toronto, ON, Canada. 
Received: 4 September 2020 Accepted: 13 December 2020

Published online: 19 March 2021

\section{References}

1. Singer M, Deutschman CS, Seymour C et al (2016) The third international consensus definitions for sepsis and septic shock (sepsis-3). JAMA J Am Med Assoc 315:801-810. https://doi.org/10.1001/jama.2016.0287

2. Rudd KE, Johnson SC, Agesa KM et al (2020) Global, regional, and national sepsis incidence and mortality, 1990-2017: analysis for the Global Burden of Disease Study. Lancet (London, England) 395:200-211. https://doi. org/10.1016/S0140-6736(19)32989-7

3. Reinhart K, Daniels R, Kissoon N et al (2017) Recognizing sepsis as a global health priority - a WHO resolution. N Engl J Med 377:414-417. https://doi.org/10.1056/NEJMp1707170

4. Stearns-Kurosawa DJ, Osuchowski MF, Valentine C et al (2011) The pathogenesis of sepsis. Annu Rev Pathol 6:19-48. https://doi.org/10.1146/annurev-pathol-011110-130327

5. Lelubre C, Vincent J-LL (2018) Mechanisms and treatment of organ failure in sepsis. Nat Rev Nephrol 14:417-427. https://doi.org/10.1038/s41581-018-0005-7

6. Marshall JC (2014a) Why have clinical trials in sepsis failed? Trends Mol Med 20:195-203. https://doi.org/10.1016/j. molmed.2014.01.007

7. Woitowich NC, Beery A, WoodruffT (2020) A 10-year follow-up study of sex inclusion in the biological sciences. Elife. https://doi.org/10.7554/eLife.56344

8. Avey MT, Moher D, Sullivan KJ et al (2016) The devil is in the details: incomplete reporting in preclinical animal research. PLoS ONE 11:e0166733. https://doi.org/10.1371/journal.pone.0166733

9. Bara M, Joffe AR (2014) The ethical dimension in published animal research in critical care: the public face of science. Crit Care 18:R15. https://doi.org/10.1186/cc13694

10. Percie du Sert N, Hurst V, Ahluwalia A et al (2020) The ARRIVE guidelines 2.0: updated guidelines for reporting animal research. PLoS Biol 18:e3000410. https://doi.org/10.1371/journal.pbio.3000410

11. Mai S, Khan M, Liaw P, Fox-Robichaud AE (2012) Experimental sepsis models. In: Azevedo L (ed) Sepsis - an ongoing and significant challenge. IntechOpen. https://doi.org/10.5772/52876. https://www.intechopen.com/books/sepsi s-an-ongoing-and-significant-challenge/experimental-sepsis-models

12. Merkow JS, Hoerauf JM, Moss AF et al (2018) Animal experimental research design in critical care. BMC Med Res Methodol 18:71. https://doi.org/10.1186/s12874-018-0526-6

13. Lalu MM, Sullivan KJ, Mei SH et al (2016) Evaluating mesenchymal stem cell therapy for sepsis with preclinical metaanalyses prior to initiating a first-in-human trial. Elife. https://doi.org/10.7554/eLife.17850

14. Lamontagne F, Briel M, Duffett M et al (2010) Systematic review of reviews including animal studies addressing therapeutic interventions for sepsis. Crit Care Med 38:2401-2408. https://doi.org/10.1097/CCM.0b013e3181fa0468

15. Llovera G, Liesz A (2016) The next step in translational research: lessons learned from the first preclinical randomized controlled trial. J Neurochem 139(Suppl):271-279. https://doi.org/10.1111/jnc.13516

16. Dechartres A, Boutron I, Trinquart L et al (2011) Single-center trials show larger treatment effects than multicenter trials: evidence from a meta-epidemiologic study. Ann Intern Med 155:39-51. https://doi.org/10.7326/0003-4819155-1-201107050-00006

17. Jones SP, Tang X-L, Guo Y et al (2015) The NHLBI-sponsored Consortium for preclinicAl assESsment of cARdioprotective therapies (CAESAR): a new paradigm for rigorous, accurate, and reproducible evaluation of putative infarct-sparing interventions in mice, rabbits, and pigs. Circ Res 116:572-586. https://doi.org/10.1161/CIRCRESAHA.116.305462

18. Boltze J, Wagner D-C, Henninger N et al (2016) Phase III preclinical trials in translational stroke research: community response on framework and guidelines. Transl Stroke Res 7:241-247. https://doi.org/10.1007/s12975-016-0474-6

19. Hunniford VT, Grudniewicz A, Fergusson DA et al (2019) Multicenter preclinical studies as an innovative method to enhance translation: a systematic review of published studies. bioRxiv 591289. https://doi.org/10.1101/591289

20. Llovera G, Hofmann K, Roth S et al (2015) Results of a preclinical randomized controlled multicenter trial (pRCT): anti-CD49d treatment for acute brain ischemia. Sci Transl Med 7:299ra121. https://doi.org/10.1126/scitranslm ed.aaa9853

21. Osuchowski MF, Ayala A, Bahrami S et al (2018) Minimum quality threshold in pre-clinical sepsis studies (mqtipss): an international expert consensus initiative for improvement of animal modeling in sepsis. Shock 50:377-380. https ://doi.org/10.1097/SHK.0000000000001212

22. Yang J, Selvaganapathy PR, Gould TJ et al (2015) A microfluidic device for rapid quantification of cell-free DNA in patients with severe sepsis. Lab Chip 15:3925-3933. https://doi.org/10.1039/c5/c00681c

23. Mclntyre LA, Stewart DJ, Mei SHJ et al (2018) Cellular immunotherapy for septic shock. A phase I clinical trial. Am J Respir Crit Care Med 197:337-347. https://doi.org/10.1164/rccm.201705-10060C

24. Dos Santos C, Hussain SNA, Mathur S et al (2016) Mechanisms of chronic muscle wasting and dysfunction after an intensive care unit stay. A pilot study. Am J Respir Crit Care Med 194:821-830. https://doi.org/10.1164/rccm.20151 2-23440C

25. Maertens O, McCurrach ME, Braun BS et al (2017) A collaborative model for accelerating the discovery and translation of cancer therapies. Cancer Res 77:5706-5711. https://doi.org/10.1158/0008-5472.CAN-17-1789

26. Gohar F, Gohar A, Hülskamp G, Debus O (2018) The translational medicine professional: a bridge between bench and bedside? Front Med 5:294. https://doi.org/10.3389/fmed.2018.00294

27. Canadian Institutes of Health Research (2015) Guide to knowledge translation planning at CIHR: integrated and end-of-grant approaches. http://www.cihr-irsc.gc.ca/e/45321.html

28. Fergusson D, Monfaredi Z, Pussegoda K et al (2018) The prevalence of patient engagement in published trials: a systematic review. Res Involv Engagem 4:17. https://doi.org/10.1186/s40900-018-0099-x 
29. Domecq JP, Prutsky G, Elraiyah T et al (2014) Patient engagement in research: a systematic review. BMC Health Serv Res 14:89. https://doi.org/10.1186/1472-6963-14-89

30. Duffett $L$ (2017) Patient engagement: What partnering with patient in research is all about. Thromb Res 150:113120. https://doi.org/10.1016/j.thromres.2016.10.029

31. Networks of Centres of Excellence of Canada (2016) NCE glossary. https://www.nce-rce.gc.ca/Grantees-Titulaires/ Glossary-Glossaire_eng.asp

32. Nandi M, Jackson SK, Macrae D et al (2020) Rethinking animal models of sepsis-working towards improved clinical translation whilst integrating the 3Rs. Clin Sci 134:1715-1734. https://doi.org/10.1042/CS20200679

33. Stanski NL, Wong HR (2020) Prognostic and predictive enrichment in sepsis. Nat Rev Nephrol 16:20-31. https://doi. org/10.1038/s41581-019-0199-3

34. Osuchowski MF, Craciun F, Weixelbaumer KM et al (2012) Sepsis chronically in MARS: systemic cytokine responses are always mixed regardless of the outcome, magnitude, or phase of sepsis. J Immunol 189:4648-4656. https://doi. org/10.4049/jimmunol.1201806

35. Laudanski K, Lapko N, Zawadka M et al (2017) The clinical and immunological performance of 28 days survival model of cecal ligation and puncture in humanized mice. PLoS ONE 12:e0180377. https://doi.org/10.1371/journ al.pone.0180377

36. Law AC, Stevens JP, Walkey AJ (2019) National trends in timing of death among patients with septic shock, 1994-2014. Crit Care Med 47:1493-1496. https://doi.org/10.1097/CCM.0000000000003956

37. Marshall JC (2014b) The PIRO (predisposition, insult, response, organ dysfunction) model: toward a staging system for acute illness. Virulence 5:27-35. https://doi.org/10.4161/viru.26908

38. Mai SHC, Sharma N, Kwong AC et al (2018) Body temperature and mouse scoring systems as surrogate markers of death in cecal ligation and puncture sepsis. Intensive Care Med Exp 6:20. https://doi.org/10.1186/s4063 5-018-0184-3

39. Baker M (2019) Animal registries aim to reduce bias. Nature 573:297-298. https://doi.org/10.1038/d41586-01902676-4

40. McGinn R, Fergusson DA, Stewart DJ et al (2020) Surrogate humane endpoints in small animal models of acute lung injury: a modified Delphi consensus study of researchers and laboratory animal veterinarians. Crit Care Med. https:// doi.org/10.1097/CCM.0000000000004734

\section{Publisher's Note}

Springer Nature remains neutral with regard to jurisdictional claims in published maps and institutional affiliations.

\section{Submit your manuscript to a SpringerOpen ${ }^{\circ}$ journal and benefit from:}

- Convenient online submission

- Rigorous peer review

- Open access: articles freely available online

- High visibility within the field

Retaining the copyright to your article

Submit your next manuscript at $\boldsymbol{\Delta}$ springeropen.com 